\title{
Para "descolonizar" o comum \\ Um ensaio crítico sobre a obra de Dardot e Laval
}

\author{
Rafael Afonso da Silva* \\ https://orcid.org/0000-0003-4701-3565
}

Introdução

Dardot e Laval (2017) têm se destacado por introduzir aportes originais para o debate sobre o comum. Sem negar a relevância da contribuição dos autores, sustento que sua proposta de refundação conceitual do comum deve passar ainda pelo crivo crítico do pensamento descolonizador.

Em sentido oposto à tendência de guetização intelectual, que gera fronteiras artificiais entre correntes de pensamento, ao mesmo tempo que invisibiliza suas diferenças internas, valho-me do termo pensamento descolonizador para abranger um território vasto e incongruente de correntes e autores que: 1) valorizam a multiplicidade ontológica (ou dos modos de ser no mundo) e a diversidade epistemológica do mundo e 2) buscam promover formas de descolonizar o conhecimento e suas práticas e de produzir pluralismos articulados "na linha de uma mestiçagem descolonizada cuja mistura de conhecimentos, culturas, subjetividades e práticas subverta a linha abissal em que se baseiam as epistemologias do Norte" (Santos, 2019, p. 161).

Argumento que há, na conceituação do comum por Dardot e Laval, elementos que podem ser incorporados como recursos conceituais para descolonizar os pensamentos e as práticas do comum. Por outro lado, essas potencialidades "decoloniais" tendem a ser limitadas por dispositivos epistêmicos que repõem "a linha abissal em

* Universidade Estadual de Campinas, São Paulo, Brasil. 
que se baseiam as epistemologias do Norte”. A crítica a esses dispositivos conduz à (meta)norma da inapropriabilidade epistêmica como premissa (decolonial) da política do comum.

\section{Potências "decoloniais" do comum em Dardot e Laval}

Uma das vantagens da abordagem do comum em Dardot e Laval (2017) é o modo como eles vinculam sua efetivação à prática dos próprios coletivos, demandando o deslocamento de conteúdos prescritivos, fundados em tentativas de estabelecer aprioristicamente o que deve ser posto em comum, os contornos normativos do comum ou os seus sujeitos.

Em uma elaboração que parece retomar a perspectiva de Linebaugh (2013, p. 285) do comum "como verbo, como atividade", como commoning (fazer-comum), eles localizam o fundamento do comum no agir comum. Este designa "o fato de que os homens se engajam juntos em uma mesma tarefa e, agindo desse modo, produzem normas morais e jurídicas que regulam a ação" ou "a ação que institui o comum e dele se encarrega" (Dardot \& Laval, 2017, p. 25). Desse modo, o comum não é legenda reservada a um conjunto predefinido de "bens". Comum é uma qualidade que deriva da ação e não das coisas, descrevendo "ao mesmo tempo uma qualidade do agir e aquilo que é instituído por esse mesmo agir" (Idem, p. 297).

Analogamente, o comum não é atividade reservada a um conjunto predefinido de sujeitos, como acontecia, por exemplo, em certas linhagens marxistas que atribuíam ao proletariado o estatuto de agente privilegiado da revolução social. A discussão dos dois intelectuais franceses recorda o modo como Linebaugh (2013) identifica o fundamento da articulação entre commoners (comuneiros) e commons (recursos comuns) no commoning (fazer-comum), projetando as três categorias como "tríade indissociável” (Tonucci Filho, 2019, p. 162). Com efeito, o duplo referente do comum - como "qualidade do agir" e como "aquilo que é instituído por esse mesmo agir" - articula-se a um sujeito coletivo concebido como contemporâneo da própria instituição do comum como regime de práticas: “[... ] somente a atividade prática pode produzir um novo sujeito coletivo, em vez de afirmar que tal sujeito preexista a essa atividade" (Dardot \& Laval, 2017, p. 53). É na e pela participação na mesma atividade e em seu governo que se autoproduz o sujeito coletivo do comum.

A partir da centralidade do agir comum, Dardot e Laval argumentam que o que distingue seu regime de práticas é a coimplicação de coparticipação, codecisão e coobrigação políticas. O termo "comum", pela própria raiz etimológica latina da palavra (cum + munus, obrigação), parece apto a reivindicar o princípio político da coobrigação. $\mathrm{O}$ essencial, no entanto, seria a natureza derivada da coobrigação, 
que resultaria da participação em uma mesma atividade e da codecisão relativa às regras que a governam: "A obrigação política procede inteiramente do agir comum, extrai sua força do compromisso prático que une todos os que elaboram juntos as regras de sua atividade, e vale apenas para os participantes de uma mesma atividade" (Idem, p. 616).

Subjacente à noção dessa tríade, encontra-se a noção de instituição. O comum é instituído por uma prática e mantém-se nela e por ela, ou seja, não preexiste à sua instituição e não sobrevive a ela. Em um diálogo crítico com a noção de "poder instituinte”, de Castoriadis, e de "práxis”, de Marx, Dardot e Laval propõem o conceito de práxis instituinte como "a atividade que estabelece um novo sistema de regras $e$ a atividade que tenta reiniciar permanentemente esse estabelecimento para evitar a paralisação do instituinte no instituído" (Idem, 471). O comum deve ser compreendido como práxis instituinte que estabelece "as regras do uso comum e de seu prolongamento em um uso instituinte que proceda à revisão regular dessas mesmas regras" (Idem, p. 504).

À centralidade da noção de instituição corresponde a proposição de uma lógica federativa na relação entre comuns. Entre os múltiplos comuns e sujeitos coletivos autoproduzidos na sua instituição, não pode haver senão federações ou comuns de comuns, que têm como base os mesmos fundamentos que definem o comum como princípio político. Essa política de comuns de comuns, estendida tanto à esfera socioeconômica como à esfera política pública, é o fundamento de "uma democracia dos comuns" (Idem, p. 619).

Para fechar o círculo da elaboração conceitual dos autores, falta dizer que a inapropriabilidade é a norma transversal do comum como princípio político. O comum não é o fundamento de um direito de propriedade sobre uma coisa, mas sua negação em todas as formas, pois o que ele visa é o governo de sua apropriação-destinação, devendo, assim, ser subtraído de toda apropriação-pertencimento. A instituição do comum é a coinstituição contínua das regras do uso comum, da apropriação-destinação de algo que se torna, por esse uso, inapropriável ou indisponível para sua apropriação-pertencimento (Idem, p. 620).

Ao estabelecer tais premissas, Dardot e Laval criam um espaço analítico e político que apresenta muitas afinidades com o pensamento descolonizador, na medida em que recusa um monopólio normativo para o comum na forma de uma plataforma epistemológica e política que defina aprioristicamente os sujeitos, os objetos, as formas ou modalidades do comum. O que dá forma ao comum é "a prática de governo dos comuns pelos coletivos que lhe dão vida” (Idem, p. 618). Essa perspectiva implica o deslocamento da possibilidade de um "ponto zero" (Castro-Gomez, 2004) para o comum, quer dizer, de qualquer referência normativa representada como externa às 
práticas de instituição do comum ou como um dispositivo situante (social e culturalmente) não situado. Esse deslocamento é um pressuposto para assegurar o lugar da multiplicidade ontológica ou cosmopolítica e da diversidade epistemológica do mundo na política do comum.

A aptidão "decolonial" dessas elaborações é reforçada por um conjunto de críticas que diz respeito a usos correntes do comum. Gostaria de destacar as críticas à concepção naturalista do comum, à identificação do comum ao universal e aos modelos teleológicos da emergência do comum.

Federici (2014) observa que a revalorização dos comuns não é tendência exclusiva de pessoas e grupos comprometidos com valores solidários ou com uma perspectiva anticapitalista. Mesmo economistas ortodoxos do livre mercado reconhecem que a mercantilização de todas as esferas da vida pode ser contraproducente para o capital e estão "aprendendo quais são as virtudes dos 'bens comuns”" (Idem, p. 148) e como reorientá-las em benefício dos interesses da acumulação de capital. A apropriação da linguagem dos comuns pelo Banco Mundial e pela ONU e a atribuição do Prêmio Nobel de Economia de 2009 a Elinor Ostrom, por sua obra sobre o "governing the commons", são expressões dessa tendência.

Dardot e Laval salientam que, na base dos discursos que procuram reviver os comuns dentro de um apelo pragmático relativo às suas virtudes racionais para a gestão de certos bens específicos, encontra-se uma concepção naturalista do comum. O sucesso de Ostrom, por exemplo, repousaria na defesa de uma distribuição naturalizada de bens de acordo com o regime institucional (privado, estatal ou comum) mais apropriado à sua gestão. A escolha institucional pelo comum ou pelo privado ou público decorreria do caráter intrínseco (natural) do bem, impondo-se aos cálculos dos indivíduos (naturalmente racionais) graças à sua racionalidade superior para a gestão desse bem específico.

Essa concepção impede a construção do comum como "princípio geral de reorganização da sociedade", definindo um regime de diversidade institucional em que é reservado para os comuns o lugar de uma economia especial de certo tipo de recursos, uma espécie de "arquipélago" no oceano de uma economia maior dominada pelo mercado (Dardot \& Laval, 2017, pp. 164-165). Além disso, esse esquema ancora-se em um tipo antidemocrático de autoridade, na medida em que caberia a economistas, juristas ou outros especialistas, à revelia de coletivos e movimentos, a tarefa de alocar os bens, por sua suposta natureza, nos regimes institucionais apropriados. A naturalização do comum alinha-se, assim, com uma forma de naturalização da autoridade.

A refundação conceitual do comum por Dardot e Laval contrapõe-se radicalmente a essa captura (colonial) do comum. Pode-se dizer que ela opõe ao discurso da diversidade institucional naturalizada, baseada nos interesses do mercado, o dis- 
curso da diversidade da práxis instituinte do comum, baseada nas práticas coletivas e nas lutas políticas, como fundamento não naturalista da política do comum como "princípio geral de reorganização da sociedade".

Concorre com a perspectiva da diversidade da práxis instituinte do comum a perspectiva que identifica o comum com o universal. Trata-se daquelas tradições que definem o comum pelo "humano", quer dizer, pelo que é comum ao gênero humano e, portanto, universal, reconduzindo a conceituação do comum a um essencialismo em que, "ao contrário do anterior, a identidade interna do gênero substitui a identidade material das coisas" (Dardot \& Laval, 2017, p. 45). O discurso dos direitos humanos universais pertence a esse conjunto de tradições, assumindo a especificação abstrata de um "homem universal" ou "cidadão universal" prototípico como seu destinatário genérico ou a "comunidade" prototípica como sujeito de uma titularidade universal.

Não é difícil imaginar que esse essencialismo da "identidade interna do gênero" não funcione sem algum tipo de "razão legisladora" (Bauman, 1999) que, a partir de uma ontologia do gênero humano, seja capaz de indicar o que é universal e, assim, de demonstrar a necessidade de universalizar certo conjunto de significados, de objetos, de instituições, de modos de ser concebidos como comuns, universais, racionais. A universalidade abstrata dessa ontologia é evidentemente ancorada em pressupostos ocidentalocêntricos. Como afirma Mignolo (2008, p. 300), "a defesa da similaridade humana sobre as diferenças humanas é sempre uma reivindicação feita pela posição privilegiada da política de identidade no poder".

A oposição de Dardot e Laval a tal concepção reitera motivos importantes do pensamento descolonizador, designadamente, a crítica da imperialidade ou colonialidade embutida na visão dominante da universalidade e a ideia de um "projeto global [...] que seria - ao contrário de Kant - pluriversal em vez de universal" (Mignolo, 2017, p. 14). Em oposição à universalidade abstrata do gênero humano, Dardot e Laval (2017, pp. 52-53) enfatizam que "o comum deve ser pensado como coatividade", o que demanda "provincianizar" a noção de universalidade: "Se existe 'universalidade', só pode tratar-se de uma universalidade prática, ou seja, a de todos os indivíduos que, em dado momento e em dadas condiçôes, se encontram engajados numa mesma tarefa”.

Por fim, a crítica aos modelos teleológicos da emergência do comum: os modelos da emergência espontânea do comum a partir do social e da produção histórica do comum pelo capital. O primeiro explica a emergência do comum a partir da própria natureza da vida social, que conteria, em si mesma, um dinamismo conducente à cooperação e à reciprocidade, de modo que o desenvolvimento do comum dependeria somente da supressão de instituições consideradas antissociais ou artificiais, como a propriedade privada, em Proudhon, ou as instituições do capital financeiro, 
na literatura mais otimista em relação às virtudes das redes e do trabalho imaterial no contexto do capitalismo contemporâneo. O segundo refere-se à noção (que remontaria a Marx) de que as formas da cooperação produtiva desenvolvidas pelo capital, as formas de "socialização" gestadas no processo de acumulação do capital, constituem a condição material da gestão coletiva da produção pelos trabalhadores, o fundamento da produção consciente de outro regime (comum) de propriedade e de relações de produção.

A cumplicidade de certos discursos teleológicos com a produção e a reprodução da relação colonial/imperial foi denunciada por autores do pensamento descolonizador. São discursos que participam do que Santos (2008) designa como "monocultura do tempo linear". A ideia do tempo linear localiza na "frente do tempo" instituições, formas de sociabilidade e conhecimentos da metropolitanidade, convertendo-os na norma temporal de uma assimetria de corte colonial/imperial.

É essa a lógica que Dardot e Laval criticam nos modelos teóricos acima, denunciando a neutralização social das formas existentes de cooperação ou, de maneira mais específica, a subestimação dos dispositivos de poder por meio das quais o capital molda as formas de cooperação, seja na grande indústria do século XIX, seja na atual economia do conhecimento. Embora concebam de modo muito distinto a produção do comum, ambos os modelos têm como consequência desativar a práxis instituinte do comum, em benefício das formas (instituídas) de subsunção do trabalho ao capital. Para escapar a esses modelos, Dardot e Laval propõem recusar os seus postulados e aderir a um modelo teórico que tenha como ponto de partida as "práticas coletivas e as lutas políticas" como "fontes de instituição e de direito" (Idem, p. 240).

Esse conjunto de críticas tende a endossar e a fundamentar um lugar para uma política pluriversal (decolonial) do comum, contrapondo-se à captura (colonial) do comum pelos mecanismos da diversidade institucional naturalista, alinhada ao mercado, da universalidade monocêntrica, típica da imperialidade/colonialidade, e da norma temporal das teleologias capitalocêntricas do Norte. É a perspectiva radicalmente construcionista do comum desenhada pelos autores - a qual pode ser sintetizada na ideia de que não há outra medida do comum senão as regras estabelecidas pelos coletivos que se autoproduzem na instituição do comum - que lhes permite descartar essas medidas/normas da imperialidade/colonialidade.

\section{Armadilhas "coloniais" do comum em Dardot e Laval}

Defendo que os aspectos da obra de Dardot e Laval acima apresentados podem ser incorporados como importantes recursos conceituais em benefício da descoloniza- 
ção da política do comum. Para isso, é necessário, contudo, aprender a manejá-los para além dos limites coloniais que Dardot e Laval tendem a reinstalar em sua obra.

Refiro-me, em primeiro lugar, a uma "arqueologia do comum" que repõe armadilhas epistemológicas ou cosmopolíticas de matriz colonial/imperial. Ao falar de arqueologia do comum, não aludo apenas ao primeiro capítulo da obra de Dardot e Laval (2017), assim intitulado, mas à arqueologia de saberes e práticas ou ao estudo da "história longa" do comum que atravessa todo o livro, explorando possibilidades e limites de experiências sociais e teorias ou paradigmas do comum. Considerando que essa arqueologia incide sobre o significado, a justificação e a orientação das lutas em torno do comum, não se pode subestimar a relevância de desenvolver crítica atenta de seus pressupostos.

Ao passar em revista os capítulos do livro, torna-se claro que a arqueologia do comum de Dardot e Laval permanece dentro dos limites do cânone ocidental. Podemos começar observando que o estudo da "longa história" do comum começa, como de praxe nas metanarrativas eurocêntricas, com antigos gregos e latinos. A essas "raízes" é atribuído um sentido especial, prototípico ou matricial, para a política do comum. No contexto das proposições políticas do livro, reafirma-se essa precedência, quando se diz que a política do comum "tem raízes na tradição política da democracia, em especial na experiência grega” (Idem, p. 485). Esse enunciado não é destituído de implicações, determinando o privilégio da experiência grega e, assim, a política de "raízes" típica do "racismo epistêmico" (Maldonado-Torres, 2008).

É verdade que Dardot e Laval (2017, p. 116) reconhecem que foram movimentos latino-americanos, como dos piqueteiros e das fábricas recuperadas na Argentina, da "guerra do gás" e da "guerra da água" na Bolívia, das comunidades indígenas de Chiapas no México etc. que começaram, a partir da década de 1990, a "popularizar o 'retorno dos comun'”. Esse reconhecimento, no entanto, não se desdobra na investigação de suas instituições, de seus regimes de práticas, discursos e conceitos.

Embora registrem, de passagem, a inspiração ameríndia dos movimentos do retorno dos comuns na América Latina e a reativação de "antigas formas deliberativas comunitárias" (Idem, pp. 116-117), o capítulo sobre a arqueologia do comum nada diz a respeito dessas "raízes", ao passo que não deixa de citar Aristóteles, Cícero, Virgílio, Santo Agostinho e Kant. Para essa arqueologia, parece importante retomar a concepção aristotélica da instituição do comum (koinón) e do pôr em comum (koinónein), mas não a concepção de colaboração ou trabalho mútuo (minga), de compromisso recíproco (mita) e de complementaridade/participação (pacta-pacta) como fórmula de governo do repertório da tradição comunal andina dos Ayllu, por exemplo.

Ao examinar o retorno dos comuns, nossos autores estão mais interessados em subsumir sua heterogeneidade sob um rótulo genérico do que "nos sentidos diferentes 
que o termo 'comuns' pode assumir no novo léxico político” (Idem, p. 103). Assim é que as experiências e os "sentidos diferentes" do retorno dos comuns podem ser reduzidos a uma porção pequena de enunciados acerca de sua oposição a "aspectos perniciosos e intoleráveis das políticas neoliberais" ou às dinâmicas pervasivas do "cosmocapital" (neoliberal) e acerca de sua "exigência de uma nova forma, mais responsável, duradoura e justa, de gestão 'comunitária' e democrática dos recursos comuns" (Idem, p. 115; 105). Com isso, extingue-se o interesse de Dardot e Laval por esses movimentos, e eles podem passar à crítica aos limites dos paradigmas dominantes na análise dos comuns.

Mais problemático, porém, é o tratamento da África na discussão do livro. Ao tratar da "ilusão da propriedade coletiva arcaica", os autores se referem à "situação da África, onde ainda existem partidários da ideia de propriedade coletiva da terra" (Idem, p. 262). Além de uma breve menção à concessão estatal de terras a multinacionais na Etiópia, na introdução do livro (Idem, p. 19), essa é a única referência à África. O objetivo da seção a que pertence essa referência é refutar a tese de que alguma vez houve algo que autorize a sustentar o conceito de "propriedade comum" como base para o comum. Não interessa considerar aqui a questão, mas o modo como a África aparece nesse contexto.

A principal referência para a construção do argumento dessa seção é a obra do antropólogo neoevolucionista francês Alain Testart. São as tipologias que ele estabelece na captura do "sentido da evolução social" que interessam a Dardot e Laval, particularmente duas: uma que se refere ao sentido da evolução da propriedade (exposta em três "mundos") e outra que compreende o sentido da evolução do sistema político nas "sociedades com riqueza e propriedade usufundada" ("mundo II" da primeira tipologia). Trata-se de tipologias triádicas, como costumam ser as tipologias ocidentais "clássicas", com sua obsessão simétrica, tipologias que se apresentam como grades de interpretação da diversidade a partir de referenciais cuja "neutralidade" não é questionada. A partir dessas duas tipologias, a África emerge como lugar de "sociedades com riqueza e propriedade usufundada", provavelmente com desigualdades e hierarquias pronunciadas, e como lugar de sociedades em que a "democracia primitiva” deu lugar à “organização em linhagens”. Com efeito, em relação à terceira categoria de sociedade da segunda tipologia, caracterizada pela "organização em linhagens", lemos que é "típica da África” (Dardot \& Laval, 2017, p. 259).

Dardot e Laval não questionam a ideia de um "sentido da evolução social", que está na base das tipologias de Testart. Não questionam também suas outras premissas. A oposição entre democracia e organização em linhagens, por exemplo, não é colocada em questão. Além disso, o interesse em afirmar que as formas de propriedade usufundada (em que se basearia a "ilusão da propriedade coletiva arcaica”) não 
excluem desigualdades e hierarquias é maior do que o de ocupar-se com os regimes de prática de possíveis culturas comunais que existiram ou existem fora das premissas dos “mundos I, II e III" de Testart.

Para mais, importa registrar a utilização acrítica de uma ideia de África homogênea. Ao tratar da "situação da África", após descartar a "aldeia" como candidata à detentora de uma suposta propriedade coletiva da terra, Dardot e Laval (2017, p. 262) concluem, com uma citação de Testart, que "os homens e suas famílias é que são os verdadeiros proprietários da terra na África”. Esse modo de considerar a questão da propriedade na África contrasta com o modo como os autores abordam, nesse mesmo capítulo, a "herança normativa ocidental", que, segundo eles, não pode ser examinada como "um maciço homogêneo" (Idem, p. 290). É a colonialidade representacional que orienta esse discurso, que apresenta a "herança normativa ocidental" como diversificada e os dispositivos comunitários de uso/distribuição da terra na África como "um maciço homogêneo".

É importante observar que, no contexto das lutas pela terra no continente africano, o enunciado dos "verdadeiros proprietários” tem sido manipulado em oposição às instituições das diversas culturas comunais e em benefício do açambarcamento de terras pelas estruturas de poder transnacionais. Isso ocorre tanto quando o enunciado é interpretado no sentido da formalização jurídica de títulos individuais de propriedade dos homens e de suas famílias, como quando orientado para o reconhecimento da propriedade coletiva, dentro de arranjos que garantem o direito de alienação da terra e favorecem o desenvolvimento de mercados fundiários (Federici, 2011). O que esse tipo de enunciado omite, como alerta Segato (2014), é que normas comunitárias, como as que regulam o uso e a distribuição da terra, não podem ser compreendidas fora da "forma holística" em que são concebidas e funcionam, quer dizer, fora da sua conexão indissociável com outras normas, relacionadas com outros aspectos da vida comunitária. Para usar os termos de Dardot e Laval, podemos dizer que as formas de “apropriação-destinação" da terra não podem ser inferidas de regras de "apropriação-pertencimento" isoladas. O isolamento e a juridicização dessas regras pertencem ao contexto pós-intrusão colonial moderna e participam do movimento de eliminação das culturas comunais na África.

Como sublinha Federici (2011, p. 42), “os comuns não podem ser vistos como realidades não problemáticas”. No continente africano, os comuns referem-se não somente a uma diversidade de comunidades e instituições comunitárias, mas constituem realidades em mutação. Em primeiro lugar, a intrusão colonial desfigurou e desfigura suas instituições, introduzindo elementos de ruptura do tecido coletivo (Segato, 2014). Em segundo lugar, emergem movimentos diversos, alguns orientados para a erradicação das regras costumeiras, tornadas opressivas ou mais opressivas 
no contexto pós-intrusão (a exemplo do que acontece com regras "masculinas" de posse da terra sem o contrapeso de outras instituições comunitárias), outros, para sua reconstituição e sua revisão sob princípios de um igualitarismo comunal desgenerizado e radicalizado (Federici, 2011). Por fim, outros comuns aparecem no cenário, revivendo e transformando culturas comunais "tradicionais", como nas hortas urbanas de mulheres (Idem). Penso que um livro sobre o comum, ao falar da África, deveria ocupar-se dessa complexidade e estudar seriamente as instituições do fazer-comum pré-intrusão, reconstruídas através das histórias orais, e as instituições do fazer-comum atuais e emergentes, consideradas no contexto específico dos efeitos da intrusão colonial moderna e da atuação de agentes do "anticomum”, como o Banco Mundial, o FMI e as frentes estatais-empresariais-midiáticas-evangélicas.

A arqueologia do comum de Dardot e Laval ressente-se da "ignorância ignorante do Norte Global”, repondo o mecanismo “do des-pensamento e da desaprendizagem de saberes não ocidentais ou não imperiais" (Santos, 2008, p. 39) ou a "razão etnológica" de uma "biblioteca colonial”, com seus "regimes de verdade" (Mudimbe, 2013). Enquanto reafirma o valor da língua grega como "língua política por excelência" (Dardot \& Laval, 2017, p. 25), por exemplo, ela ignora sistematicamente os discursos, os léxicos, as "línguas políticas” do Sul. Entre a discussão da concepção aristotélica do pôr em comum, no primeiro capítulo, e das tradições do "comum dos operários", no capítulo 9, são experiências europeias (e autores europeus e estadunidenses) que ocupam um lugar central na arqueologia de Dardot e Laval.

Uma arqueologia é, claro, sempre limitada, mas, do ponto de vista do pensamento descolonizador, é importante interrogar o campo de possibilidades que a "razão imperial/colonial" alijou para fora dos limites do que é considerado compreensível ou relevante, as possibilidades inscritas nas línguas e formas de pensar e nas experiências sociais marginalizadas pelo pensamento ocidental hegemônico. Como diz Mignolo (2008, p. 292), interessa inaugurar "uma genealogia de pensamento que não é fundamentada no grego e no latim, mas no quechua e no aymara, nos nahuatls e tojolabal, nas línguas dos povos africanos escravizados [...] que reemergiram no pensamento e no fazer decolonial verdadeiro: Candomblés, Santería, Vudú, Rastafarianismo, Capoeira etc.”. Nesse sentido, uma arqueologia do comum deve dirigir-se ao "idioma” (cosmopolítica) de outras experiências situadas para além das europeias, não somente para pensá-las a partir do comum, mas para pensar o comum a partir delas, compondo, assim, múltiplos sentidos para o comum, a partir de diversas economias ontológicas, de diversos mapas de possibilidades. Plagiando Santos (2019, p. 33), podemos dizer que, com essa perspectiva, o que se visa é instaurar, no contexto do comum, "uma concepção 'polilectal', mais do que idiolectal, de imaginação cultural e política”. 
Uma implicação dos limites "coloniais" da arqueologia do comum de Dardot e Laval é a subestimação da heterogeneidade das relações de poder e da importância da pluralização de frentes políticas relacionadas a elas para a política do comum.

Podemos começar essa discussão registrando que as palavras racismo, etnicismo, sexismo, patriarcado ou colonialismo não aparecem no livro de Dardot e Laval sobre o comum. Enquanto o comum é apresentado como "o princípio das lutas atuais contra o capitalismo" (Dardot \& Laval, 2017, p. 23), nada se diz acerca das lutas contra outras relações de poder e suas imbricações com as "lutas atuais contra o capitalismo" no contexto do atual retorno dos comuns.

Uma arqueologia do comum que considerasse seriamente suas emergências atuais no Sul global permitiria apreender que o retorno dos comuns é indissociável das lutas políticas contra relações de poder coloniais, racistas e patriarcais. A retomada (reinstituição) de antigas "genealogias" do pensar e do fazer-comum, destituídas ou marginalizadas pelo epistemicídio colonial-moderno, demonstra a importância da descolonização epistêmica/cosmopolítica na construção dos “comuns” emergentes. Essa retomada é bastante evidente justamente no contexto, destacado por Dardot e Laval, do retorno dos comuns na América Latina. Aqui movimentos indígenas têm instituído "enlaces" em diferentes escalas e manejado a "cosmovisão", isto é, as figuras emergentes da recuperação da memória histórica dos povos originários do continente, como ferramenta política dentro de uma agenda descolonizadora concêntrica à luta contra o racismo. Os movimentos de mulheres indígenas são igualmente centrais na definição do horizonte normativo e da agenda política do retorno dos comuns na América Latina, denunciando as desigualdades de gênero presentes nas comunidades como uma "deterioração" da cosmovisão sob "a influência das culturas invasoras", de "um modelo baseado em culturas ocidentais", como lemos nas atas da Primera Cumbre de Mujeres Indígenas de América, realizada em Oaxaca, em 2002 (Castillo, 2018, p. 320). É no bojo dessas lutas e na dinâmica conflitiva da pluralização e da coordenação dessas frentes políticas que se tem produzido o retorno dos comuns na América Latina.

Devemos considerar o retorno dos comuns como um produto dos "enlaces" multiescalares instituídos entre frentes e agentes plurais que lutam contra políticas neoliberais e seus efeitos, tanto quanto contra relações coloniais, racistas e patriarcais de dominação, que, aliás, não são exteriores, mas compõem os modos de emergência do neoliberalismo no continente. A ausência de uma análise dessas dimensões no livro de Dardot e Laval sobre o comum é igualmente expressão "do des-pensamento e da desaprendizagem de saberes não ocidentais ou não imperiais". 
No que concerne a essa questão em específico, esse "despensamento" ancora-se em uma equação complexa. De um lado, temos a representação do capitalismo contemporâneo a partir da coerência de uma racionalidade governamental única e abrangente, a racionalidade neoliberal, caracterizada pela penetração da lógica normativa da concorrência e do modelo da empresa em todos os contextos de atividades e relações sociais, incluindo os dispositivos de subjetivação. "O neoliberalismo", escrevem Dardot e Laval (2016, p. 17), "é a razão do capitalismo contemporâneo [...]". De outro, temos a concepção de que a "comunização" das lutas dos comuns deriva, em alguma medida, da própria unicidade da "razão do capitalismo contemporâneo".

Como Foucault, Dardot e Laval (2016, pp. 25-26) se apropriam subversivamente da perspectiva ordoliberal segundo a qual o capitalismo é um complexo "econômico-institucional" e não somente encarna a lógica de uma figura "econômica”, em sentido estrito, e, por isso, admite "uma multiplicidade de figuras singulares". Em entrevista a Andrade e Ota (2015, p. 285), sublinham que "as relações sociais próprias do capitalismo não se estendem por meio de uma dinâmica econômica passível de ser isolada das relações de poder, das construções institucionais, das formas jurídicas”. Poderíamos supor que tal asserção daria lugar a uma reflexão aberta à perspectiva da "interseccionalidade" ou da "consubstancialidade" das relações de poder. Essa linha de reflexão demandaria considerar a "multiplicidade de figuras singulares" do capitalismo em termos sincrônicos. No entanto, Dardot e Laval reencontram essa multiplicidade apenas na história de suas transformações "epocais", enquanto buscam conceituar o neoliberalismo, compreendido como "a razão do capitalismo contemporâneo", a partir de sua coerência como sistema normativo ou regime de governamentalidade.

Considero a análise do neoliberalismo como um sistema normativo, nos termos de Dardot e Laval, como uma verständige Abstraktion, abstração razoável, como diria Marx (2011), ou, como prefiro, uma abstração estrategicamente útil. Mas ela coloca em xeque sua "razoabilidade" teórica ou, do ponto de vista da "reinvenção das formas de luta” (Dardot \& Laval, 2016, p. 34), sua “utilidade”, quando leva a desconsiderar as "linhas abissais" (Santos, 2010) que distinguem as dinâmicas normativas e construções institucionais dos espaços metropolitanos (do Norte e do Norte do Sul) e coloniais (do Sul e do Sul do Norte) ou quando não aprofunda sua "razoabilidade" em face das "razões" emergentes da complexidade de sistemas dinâmicos que enredam múltiplas e heterogêneas relações de poder nos distintos contextos situados.

Em entrevista a Andrade e Ota (2015, p. 281), Dardot e Laval se referem às suas próprias investigações como "menos relacionadas à 'especificidade' dos problemas e saberes do que à coerência da racionalidade do poder e ao 'tornar comum' saberes e práticas que podem se lhe opor" e rematam dizendo que: 
Estamos em uma época em que não convém acentuar tanto a especificidade das lutas, mas a coordenação delas, até mesmo, sua "comunização" (communisation). Não que seja necessário construir uma espécie de grande teoria geral, um novo "ismo" que apague as particularidades das lutas parciais [...]. Precisamos, no entanto, de ideias claras sobre a lógica geral do poder, condição necessária para permitir tornar comuns as lutas parciais e as resistências locais.

Segundo essa perspectiva, enquanto o poder se inscreve em uma "lógica geral", as "lutas parciais" - e sua parcialidade decorre precisamente da suposição de um "geral" - apenas podem produzir os princípios de sua coordenação ou "comunização" a partir de "ideias claras" sobre aquela. Nesse sentido, a coordenação das lutas parece depender mais da unicidade da "lógica geral do poder" do que da práxis instituinte dos próprios movimentos na produção dos dispositivos de sua coordenação. Traduzindo o argumento nos termos da análise de Dardot e Laval sobre a "sociedade neoliberal", é a própria unicidade ou coerência da "razão do capitalismo contemporâneo" que parece destinada a produzir a unidade das "lutas parciais" e "resistências locais". Em outras palavras, voltamos ao modelo da "produção do comum pelo capital", mas, no lugar da "socialização" capitalista da produção ou da "livre cooperação dos cérebros" engendrada pelo "capitalismo cognitivo", o que temos é a lógica normativa una e totalizante do regime de governamentalidade neoliberal.

Essa abordagem ancora-se em um modelo que é o oposto da perspectiva da diversidade da práxis instituinte do comum e dos "enlaces" federativos baseados na produção de comuns de comuns. Ao passo que, para esta perspectiva, os motivos, os dispositivos institucionais, saberes e práticas (incluindo qualquer corpo de "ideias claras") para a coordenação dos movimentos e lutas devem ser instituídos na instituição dos comuns e dos comuns de comuns, a linguagem da "lógica geral do poder" conduz à reiteração da política de autoridade epistêmica que se pretendia eliminar junto com a concepção "naturalista" do comum, reinstalando uma assimetria que atribui vantagem epistemológica ao "trabalho teórico". A este caberia o dever de reconduzir os "sentidos diferentes" emergentes das lutas políticas a um "sentido" unificado, aquele de uma coerência política pensada (instituída) a partir do desvendamento da "coerência da racionalidade do poder". Enquanto se decreta que "não convém acentuar tanto a especificidade das lutas" ou ainda que não se deve mais investir na pluralização de frentes políticas e identidades políticas sob o risco de "fragmentação das lutas sem um horizonte comum", nossos autores concluem que "cabe ao trabalho teórico identificar o que nele [no retorno dos comuns] é portador tanto da invenção conceitual quanto do projeto político" (Andrade \& Ota, 2015, p. 312). No jogo de explicar, interpretar, traduzir e contextualizar, as instituições do "trabalho teórico" tendem, assim, a substituir aquelas das práticas coletivas e lutas políticas. 
Para ficar claro, trata-se não de negar o caráter mundial do capitalismo ou a hegemonia do neoliberalismo em sua configuração atual, mas de reconhecer que o "devir-mundo" do capital e a hegemonia do neoliberalismo não são instituídas sob a regência de uma "lógica geral de poder", mas sob processos "consubstanciais" às dinâmicas situadas "das relações de poder, das construções institucionais, das formas jurídicas" etc. Por isso, a pluralização das lutas ou "a especificidade das lutas" é tão essencial quanto sua coordenação ou "comunização". A luta "geral” contra o capitalismo não pode desenvolver-se senão por meio da pluralização das lutas (frentes e agentes) contra suas configurações situadas - constituídas como um "pacote enredado" de múltiplas e heterogêneas hierarquias (Grosfoguel, 2008) - e por meio da instituição de dispositivos multiescalares de coordenação entre elas. É dessa forma, por exemplo, que se tem produzido o "enlace continental" de movimentos indígenas latino-americanos, que, como vimos, têm se voltado para suas especificidades culturais e para as constelações específicas de relações de poder (coloniais, racistas, capitalistas, patriarcais, cristianocêntricas etc.) que afetam suas comunidades na construção dos dispositivos epistêmicos e prático-políticos de sua coordenação.

O pensamento descolonizador tem argumentado, de modo geral, a favor da valorização da pluralização de frentes políticas e mesmo das "identidades na política”, como formas de oposição à "política da identidade”, isto é, à política das identidades essencializadas produzidas por "razões imperiais” (Mignolo, 2008). Não se trata de congelar possibilidades ou sustentar a "fragmentação das lutas sem um horizonte comum", mas de assumir a necessidade de instituir os dispositivos políticos e epistêmicos do "tornar comuns as lutas" por dentro de uma "política de intermovimentos sociais" (Santos, 2008) e de uma política epistêmica de interconhecimentos sociais.

Outro efeito dos limites da arqueologia do comum de Dardot e Laval é aprisionar a "imaginação política e cultural" da política do comum a limites "idiolectais" (moderno-ocidentais) não ditos.

A crítica de Dardot e Laval ao neoliberalismo (2016) explicita que este alinha mercado e Estado à sua lógica normativa típica. Nesse contexto, dadas as condições de hibridização crescente entre as lógicas que estruturam as duas formas (privada e pública) de produção ou regulação de "bens", torna-se cada vez mais insustentável a aposta em uma alternativa derivada do "esquema binário de origem jurídica que opõe o privado e o público" (Dardot \& Laval, 2015, p. 262). 
Isso não quer dizer que, em algum momento, o Estado tenha se constituído efetivamente como plataforma legítima para a construção do comum. Embora lugares de tensão e luta, Estado e serviços públicos sempre se constituíram predominantemente a partir de um modelo burocrático de gestão, baseado na direção hierárquica e na monopolização dos processos de decisão por elites políticas e quadros burocráticos, um regime de práticas de governo avesso ao comum. O que ocorre, sob o neoliberalismo, é que este "pretende fazer desaparecer tudo aquilo que, no Estado assim como na sociedade, se assemelha a focos de resistência à norma geral da concorrência”, suprimindo qualquer base para "continuar a opor frontalmente o público e o privado, como havíamos nos habituado a fazer no passado" (Idem, pp. 267-8).

Toda essa argumentação nos leva a crer que mercado e Estado devem ser suprimidos na revolução social do comum, instaurando outro regime de práticas de governo para as atividades que eles regulam. No entanto, o que Dardot e Laval parecem propor é algo diferente:

- “Como não implica a supressão da propriedade privada, a primazia do comum não exige a fortiori a supressão do mercado” (Dardot \& Laval, 2017, p. 619). Considerando que a alternativa à supressão do mercado é a burocratização da economia, eles sustentam que não se trata de “'suprimir o mercado' em proveito de um órgão burocrático de planejamento e divisão”, mas de “reinseri-lo na sociedade”, em uma “nova instituição 'cívica' do mercado que una o autogoverno dos produtores e a soberania dos consumidores" (Idem, p. 525).

- Ao mesmo tempo que não faltam asserções acerca da incompatibilidade entre a forma estatal e a política do comum, Dardot e Laval (2017, p. 547) elogiam a concepção, forçadamente atribuída a Marx, de que “o Estado poderia 'desaparecer' como grande burocracia (a 'jiboia'), mas não deveria deixar de desempenhar o papel jurídico e simbólico de garantidor da aplicação dos princípios gerais da lei”. Quando se trata da relação do comum com o Estado, o verbo usado por Dardot e Laval é transformar, não suprimir ou destruir. A ideia parece ser, assim, de uma reinstituição, a partir do eixo do comum, daquela parte do Estado que garante a aplicação das leis e que responde pelos serviços públicos.

Pode-se dizer que, para os dois autores, a questão do mercado e a questão do Estado são pensadas, no contexto da "razão do comum", simetricamente ao modo como são tratadas pela "razão neoliberal", como questão de reinstituição dentro de um projeto construtivista baseado em uma norma. O que varia é a norma. Tal perspectiva aproxima-se de alguns motes da proposta habermasiana de um modelo que reponha a "mediação do mundo da vida" aos sistemas funcionais regidos pelos 
media dinheiro e poder, mas sem contornar, como Habermas, a empresa privada e o mundo do trabalho. Esse modelo de "reinstituição" compreende um conjunto de "não ditos" que precisam ser considerados.

A burocratização da economia não é a única alternativa ao mercado. Embora comprimidas e desfiguradas pela dominância do mercado, as experiências de redes de produção e consumo que visam a substituir os dispositivos mercantis pelo uso de outras tecnologias sociais de gestão da produção e da troca indiciam outras possibilidades. A própria perspectiva de federação de comuns socioeconômicos sugerida por Dardot e Laval (2017) autoriza a pensar em alternativas, baseadas não em "um órgão burocrático de planejamento e divisão”, mas na troca direta de atividades produtivas entre comuns socioeconômicos, de acordo com necessidades, finalidades e regras coproduzidas entre eles e dentro de uma lógica multiescalar acêntrica, e na autogestão do consumo por associações de consumidores igualmente federados em múltiplas escalas.

O mercado é passível de ser instituído de muitas maneiras, mas essa elasticidade é restringida pela mediação da forma mercadoria, baseada em "relações coisais entre pessoas e relações sociais entre coisas” e articulada à disjunção entre produção e consumo e à indiferença mútua e à conexão externa e post festum entre unidades produtivas (Marx, 2013). O neoliberalismo busca reinstituir a "ordem-quadro" do mercado e pode fazê-lo porque não pretende destituir, mas reinstituir o capitalismo, alterando o contexto institucional de funcionamento da malha de mediações sociais autonomizadas que o caracteriza. O mercado é, no entanto, incompatível com o comum, que pressupõe "relações diretamente sociais entre pessoas" (Marx, 2013) na instituição das regras do agir comum.

O "papel jurídico e simbólico de garantidor da aplicação dos princípios gerais da lei” que o Estado deveria continuar a desempenhar é necessário porque Dardot e Laval concebem o comum não somente como coprodução de regras ou normas para o agir comum, mas de regras de direito ou normas jurídicas. O direito é uma forma social historicamente específica (moderno-ocidental) de produção de normas e deve ser analisado a partir do tipo de prática social que ele possibilita ou impede e de seu significado para diferentes emergências do comum. Esse balanço analítico ainda precisa ser feito, mas há mais razões para pensar na aptidão do direito para as representações de equivalência social, próprias da forma-mercadoria (Naves, 2014), do que como modo de acolher integralmente a inequivalência das singularidades que devem participar da instituição dos comuns. De qualquer modo, é imperativo reconhecer a diversidade de modos de produtividade normativa existente no mundo - a qual frequentemente recai, inclusive entre autores vinculados ao campo decolonial ou das epistemologias do Sul, sob a legenda (inconscientemente colonial) do "pluralismo 
jurídico" - e analisar mais profundamente suas possibilidades do ponto de vista da práxis instituinte do comum.

Embora em novas figurações, Estado, direito e mercado são muito rapidamente implicados nas proposições teóricas e práticas de Dardot e Laval. Nisso aparecem como limites pré-instituidos da instituição do comum. São instituições previamente estabelecidas pelo "trabalho teórico" como condição prescritiva da instituição dos comuns. Trata-se de um curto-circuito da imaginação política produzido pelo eurocentrismo da arqueologia do comum de Dardot e Laval, que acabam enredados nos limites da "língua política" autorizada pelas instituições moderno-ocidentais.

\section{Considerações finais}

A reflexão acerca da pluralidade das experiências sociais dos comuns não deve ser considerada como um ponto de partida a ser ultrapassado por "uma concepção mais abstrata e politicamente mais ambiciosa do comum (no singular)", como sugerem Dardot e Laval (2017, p. 18). Qualquer concepção do comum (no singular) deve ser vista apenas como um recurso para a produção de comuns epistêmicos (sempre no plural), quer dizer, de plataformas cognitivas produzidas na articulação de e entre movimentos sociais do comum, ou, dito de outro modo, deve ser um recurso para a produção de pluralismos articulados na "linha da mestiçagem descolonizada" de que fala Santos (2019) no trecho citado na introdução deste artigo. Trata-se de um recurso de retaguarda politicamente pouco ambicioso e tanto mais útil quanto mais for capaz de reorientar a reflexão novamente para a pluralidade das experiências sociais dos comuns e sob uma perspectiva subversiva em relação à "linha abissal em que se baseiam as epistemologias do Norte".

A política epistêmica do comum não pode ser aquela do "trabalho teórico" pensado segundo "a primazia do conhecimento como prática social isolada" (Santos, 2019, p. 22), mas uma política de interconhecimentos sociais imersa em uma política de intermovimentos sociais. Essa perspectiva é coerente com as premissas do comum expostas na primeira seção do artigo. Ela advoga pela primazia do agir comum como práxis instituinte no contexto da política epistêmica do comum. Nesse sentido, penso que o alcance da norma da inapropriabilidade, que, segundo Dardot e Laval, está implicada na noção de comum, deve ser expandido, de modo a compreender também a norma (decolonial) da inapropriabilidade epistêmica ou, talvez seria melhor dizer, cosmopolitica. Sob tal legenda, aludo às cautelas e aos dispositivos de afirmação da pluralidade/conflitualidade dos próprios sentidos, categorias, princípios processuais, princípios formais de convivência ou de produção normativa etc. que compóem a perspectiva do comum, ou ainda às disposições e aos dispositivos que 
se contrapõem à apropriação da noção de comum por uma "língua política" ou por um regime cosmopolítico ou de ser/fazer/sentir/pensar-com.

A (meta)norma da inapropiabilidade epistêmica/cosmopolítica, porém, faz sentido apenas se estiver engajada em um movimento orientado para trazer para o centro da discussão do comum as formas de pensamento e experiências sociais não ocidentais ou não imperiais produzidas no Sul global. Nesse engajamento, ela funcionaria como um princípio de cautela contra armadilhas coloniais como aquelas em que resvalam Dardot e Laval ou como ferramenta de uma política do comum desembaraçada da "linha abissal em que se baseiam as epistemologias do Norte".

A política do comum precisa conduzir à reintrodução de uma corajosa contaminação do "imaginário crítico do 'anti-" pelo "imaginário do 'alter”" (Viveiros de Castro, 2012, p. 155), quer dizer, a uma "invasão bárbara” da perspectiva do comum pelos possíveis do Sul global. Essa contaminação só pode ocorrer por meio de ecologizações entre economias ontológicas distintas. Retomando uma formulação de Viveiros de Castro (2012), podemos dizer que, sem tal contaminação, a política do anti-conduzirá a um como-antes, repavimentando a autoestrada da colonialidade.

\section{Referências bibliográficas}

Andrade, Daniel P. \& OTA, Nilton K. (2015), “Uma alternativa ao neoliberalismo: entrevista com Pierre Dardot e Christian Laval”. Tempo Social, 27 (1): 275-315.

Castillo, Rosalva A. H. (2018), "Algunos aprendizajes en el difícil reto de descolonizar el feminismo". In: Menezes, Maria P. (org.). Epistemologías del Sur. Buenos Aires, Clacso.

Castro-Gomez, Santiago (2004), La hybris del punto cero: ciencia, raza e Ilustración en la Nueva Granada (1750-1816). Bogotá, Pontificia Universidad Javeriana.

Dardot, Pierre \& Laval, Christian. (2015), "Propriedade, apropriação social e instituição do comum”. Tempo Social, 27 (1): 261-273.

Dardot, Pierre \& Laval, Christian. (2016), A nova razão do mundo: ensaio sobre a sociedade neoliberal. São Paulo, Boitempo.

Dardot, Pierre \& Laval, Christian. (2017), Comum: ensaio sobre a revolução no século XXI. São Paulo, Boitempo.

Federici, Silvia. (2011), "Women, land struggles, and the reconstruction of the commons". The Journal of Labor and Society, 14: 41-56.

Federici, Silvia. (2014), "O feminismo e as políticas do comum em uma era de acumulação primitiva”. In: Moreno, Renata (org.). Feminismo, economia e política. São Paulo, sof.

Grosfoguel, Ramón. (2008), "Para descolonizar os estudos de economia política e os estudos pós-coloniais”. Revista Crítica de Ciências Sociais, 80: 115-147. 
Linebaugh, Peter. (2013), El Manifiesto de la Carta Magna. Madri, Traficantes de Sueños. Marx, Karl. (2013), O Capital: Crítica da economia política. Livro I. São Paulo, Boitempo.

Mignolo, Walter D. (2008), "Desobediência epistêmica: a opção descolonial e o significado de identidade em política”. Cadernos de Letras da UFF, 34: 287-324.

Mignolo, Walter D. (2017), “Colonialidade: o lado mais escuro da modernidade”. Revista Brasileira de Ciências Sociais, 32 (94): 1-18.

Mudimbe, Valentim. (2013), A invenção da África: gnose, filosofia e a ordem do conhecimento. Luanda, Pedago; Mulemba.

Naves, Márcio B. (2014), A questão do direito em Marx. São Paulo, Outras Expressões; Dobra.

SANTos, Boaventura de S. (2008), "A filosofia à venda, a douta ignorância e a aposta de Pascal". Revista Critica de Ciências Sociais, 80: 11-43.

SAntos, Boaventura de S. (2010), "Para além do pensamento abissal: das linhas globais a uma ecologia de saberes”. In: SAntos, Boaventura de S. \& Meneses, Maria Paula. Epistemologias do sul. São Paulo, Cortez.

SAntos, Boaventura de S. (2019), O fim do império cognitivo: a afirmação das epistemologias do Sul. São Paulo, Autêntica.

Segato, Rita (2014), "El sexo y la norma”. Estudos Feministas, 22 (2): 593-616.

Tonucci Filho, João Bosco M. (2019), "Além do Estado e do capital: notas sobre três abordagens críticas do comum”. Crítica Marxista, 49: 153-173.

Viveiros de Castro, Eduardo. (2012), “'Transformação’ na Antropologia, transformação da 'Antropologia'”. Mana, 18 (1): 151-171.

\section{Resumo}

Para "descolonizar" o comum: um ensaio crítico sobre a obra de Dardot e Laval

A obra de Dardot e Laval sobre o comum ainda não foi submetida ao crivo da crítica da colonialidade. Diante dessa lacuna, exploram-se, neste artigo, as potencialidades “decoloniais" dessa obra - localizando-as em sua concepção construtivista do comum -, bem como suas armadilhas "coloniais" - relacionadas com os limites eurocêntricos de sua arqueologia do comum, a subestimação da heterogeneidade das relações de poder e a dificuldade de facear os limites da "língua política" autorizada pelas instituições moderno-ocidentais. Conclui-se com um convite à expansão do imaginário político do comum a partir do repertório de experiências sociais não ocidentais/ não imperiais, sob o imperativo da norma da inapropriabilidade epistêmica ou cosmopolítica. Palavras-chave: Pierre Dardot; Christian Laval; Comum; Colonialidade. 


\section{Abstract}

To "decolonize" the common: a critical essay on the work of Dardot and Laval

Dardot and Laval's work on the common has not yet been subjected to criticism of coloniality. Faced with this gap, this article explores the "decolonial" potentialities of this work - locating them in its constructivist conception of the common - as well as its "colonial" traps - related to the Eurocentric limits of its "archeology" of the common, the underestimation of the heterogeneity of power relations and the difficulty of facing the limits of the "political language" authorized by modern-Western institutions. It concludes with an invitation to expand the political imaginary of the common from the repertoire of non-Western/ non-imperial experiences, under the imperative of the norm of epistemic or cosmopolitical inappropriability.

Keywords: Pierre Dardot; Christian Laval; Common; Coloniality.

Texto recebido em 16/10/2020 e aprovado em 1/2/2021.

DOI: 10.11606/0103-2070.ts.2021.176239.

Rafael Afonso da Silva é cientista social, com mestrado e doutorado em sociologia pela Universidade Estadual de Campinas (SP). Atualmente é profissional de Apoio a Ensino, Pesquisa e Extensão em Sociologia no Departamento de Saúde Coletiva, na Faculdade de Ciências Médicas da Universidade Estadual de Campinas, exercendo funções docentes na graduação de medicina, no Programa de Pós-graduação em Saúde Coletiva e no Programa de Mestrado Profissional Saúde Coletiva: Políticas e Gestão em Saúde. É autor de Ventos que sacodem Marx: sobre colonialismo, nacionalismo e racismo nas páginas irlandesas de Marx (2020) e de $O$ sonho curto dos napë e a pandemia(2020).E-mail: raafonso@unicamp.br. 